\title{
Design, preparation and evaluation of germicidal Toddalia asiatica herbal antiseptic detergent
}

\author{
Were L. L. Munyendo*, Ambrose K. Kiprop \\ Department of Chemistry and Biochemistry, Moi University, Eldoret, Kenya.
}

\begin{tabular}{|c|c|}
\hline ARTICLE INFO & ABSTRACT \\
\hline Article history: & \multirow{7}{*}{$\begin{array}{l}\text { To avoid skin dryness and irritation encountered with alcohol-based sanitizers, Toddalia asiatica stem bark } \\
\text { extract was explored in formulation of a germicidal herbal antiseptic detergent. A L } \mathrm{L}_{9}\left(3^{4}\right) \text { Taguchi Orthogonal } \\
\text { Array was used to optimize set factors for design and preparation. Antimicrobial activities were screened by disc } \\
\text { diffusion method for formulated herbal detergent; blank detergent; commercial handwash and tap water. A } \\
\text { model handwash efficacy experiment was carried out using volunteers, which involved enumeration of bacteria } \\
\text { from water used for palm rinsing after a hand-wash with the test agents. Freeze-drying attained } 11 \% \text { yield from } \\
500 \mathrm{~g} \text { plant material. The set factors for herbal antiseptic detergent preparation were optimized to } 10 \% \text { extract in } \\
5 \mathrm{~g} \text { of sodium lauryl salt stirring for } 15 \text { minutes at } 30^{\circ} \mathrm{C} \text {. The herbal detergent displayed highest antimicrobial } \\
\text { activity indicated by zone of inhibition diameters of } 24 \mathrm{~mm}(M . R \text {. S. aureus) and } 22 \mathrm{~mm}(\mathrm{M} \text {. gypseum }) \text { compared } \\
\text { to } 22 \mathrm{~mm} \text { and } 14 \mathrm{~mm} \text { respectively by the commercial hand wash. In the model hand wash efficacy experiment, } \\
\text { the formulated herbal detergent attained } 78.8 \% \text { reduction of pathogenic load as compared to } 67.9 \% \text { reduction } \\
\text { with the commercial handwash. The remarkable potency illustrated presents } T \text {. asiatica phytocompounds as } \\
\text { promising germicidal non-synthetic active ingredients for formulation of antiseptic detergents. }\end{array}$} \\
\hline Received on: $23 / 06 / 2016$ & \\
\hline Revised on: $14 / 07 / 2016$ & \\
\hline Accepted on: 04/09/2016 & \\
\hline Available online: $29 / 11 / 2016$ & \\
\hline Key words: & \\
\hline $\begin{array}{l}\text { Toddalia asiatica; herbal; } \\
\text { antiseptic; detergent; } \\
\text { formulation. }\end{array}$ & \\
\hline
\end{tabular}

\section{INTRODUCTION}

In the last decade, there has been an unprecedented investment in health care to accelerate the reduction of mortality. However, one of the main barriers to proven and affordable health care has been limited interventions for microbial infections (UNICEF, 2014). The skin as a protective covering of the body, averagely for an adult human being it covers a surface area of two square meters. In its intact state, the skin is a barrier, exposed to life threatening microorganisms. Meanwhile dermatology is an essential part of general medicine since diseases of the skin are a common occurrence accounting for a great deal of misery, suffering, incapacity and even economic loss (Roose-Amsaleg and Laverman, 2016). Hands have been noted to be the primary routes of transmission of multidrug resistant pathogens and other infectious germs.

\footnotetext{
* Corresponding Author

Were L. L. Munyendo, Department of Chemistry and Biochemistry, Moi University, Eldoret, Kenya.Email: munyendow @ gmail.com
}

This therefore necessitates use of antiseptic agents for washing hands and the skin (Pittet and Boyce, 2001). Currently on the market, there are alcohol-based sanitizers and chlorohexidine products as chemical antiseptics however; they have shortcomings like skin dryness and irritation as common adverse effects on frequent use (Pittet, 2005). Previously, studies have reported that resistance to the chemical antiseptics has led to outbreaks (Maury et. al., 2000; Pittet et. al., 2000).

Toddalia asiatica (L) Lam. (Rutaceae) is a medicinal plant commonly known as Orange climber (Eng.). Traditionally it is used as a browse for goats and as a hedge among the Maasai and Kipsigis communities of Kenya (Orwa et. al., 2008). The most important use of Toddalia asiatica however is medicinal. It is noted that traditional medicine treatments that exploit Toddalia asiatica are increasingly becoming common. It is used to treat skin infections, nasal and bronchial pains, stomachache, snake bites, and in rituals (Gidwani et. al., 2010). The use of T. asiatica in folk medicine to treat various ailments has been substantiated scientifically in studies focusing on phytochemical isolation, structure elucidation and antimicrobial testing. 
In one study, the ethyl acetate extract which was found to possess highest antimicrobial activity was subjected to activity guided fractionation by column chromatography over silica gel. This resulted in the isolation of the coumarin, Ulopetrol, an active principle besides Flindersine which had been reported earlier. Ulopterol showed activity against the bacteria Staphylococcus epidermidis, Enterobacter aerogenes, Shigella flexneri, Klebsiella pneumoniae, Escherichia coli and fungi Aspergillus flavus, Candida krusei and Botrytis cinerea (Karunai et. al., 2012). Much earlier, antibacterial and antifungal activities were observed in ethyl acetate extract. The active principle Flindersine (2,6-dihydro2,2-dimethyl-5H-pyrano [3,2-c] quinoline-5-one-9cl) was isolated from the ethyl acetate extract. In the study, significant inhibition was realized at quite low concentrations against bacteria Bacillus subtilis $(31.25 \mu \mathrm{g} / \mathrm{ml})$, Staphylococcus aureus $(62.5 \mu \mathrm{g} / \mathrm{ml})$, Staphylococcus epidermidis $(62.5 \mu \mathrm{g} / \mathrm{ml})$, Enterococcus faecalis (31.25 $\mu \mathrm{g} / \mathrm{ml})$, Pseudomonas aeruginosa $(250 \mu \mathrm{g} / \mathrm{ml})$, Acinetobacter baumannii $(125 \mu \mathrm{g} / \mathrm{ml})$ and fungi Trichophyton rubrum $57 \quad(62.5 \mu \mathrm{g} / \mathrm{ml})$, Trichophyton mentagrophytes $(62.5 \mu \mathrm{g} / \mathrm{ml})$, Trichophyton simii $(62.5 \mu \mathrm{g} / \mathrm{ml})$, Epidermophyton floccosum $(62.5 \mu \mathrm{g} / \mathrm{ml})$, Magnaporthe grisea $(250 \mu \mathrm{g} / \mathrm{ml})$ and Candida albicans $(250 \mu \mathrm{g} / \mathrm{ml})$ were observed (Duraipandiyan et. al., 2009). The Indian subcontinent is being considered as a vast repository of polyherbal formulations used in traditional medical treatments. The formulations are prepared by plant extracts either of the bark, leaves, stem or roots with suitable excipients standardized by various methods. A combination of chloroform extracts of leaves of Tevetia peruviana, Waltheria indica and Toddalia asiatica were used to prepare polyherbal formulations that were assessed for their cytotoxic activity by using 3-(4, 5Dimethylthiazol-2-yl)-2, 5-diphenyltetrazolium bromide (MTT) assay. Results concluded that the formulation demonstrated significant protective activity that might be due to combined effect of all these extracts (Hemalatha et. al., 2006).

Despite of its wide spread use in traditional health care systems and the variously reported In-vitro antibacterial antifungal activities, there is no report for use of $T$. asiatica extracts as the active ingredient in liquid detergents formulations. This study therefore reports for the first time design, and preparation of detergent with herbal extracts as the antiseptic agent together with a model for its evaluation as hand wash in palm rinse experiments.

\section{MATERIALS AND METHODS}

\section{Reagents}

The chemicals and solvents used were all Analar grade purchased from Kobian Kenya Ltd. Sodium hydroxide, Potassium hudroxide and sodium lauryl salt were obtained from Sigma Aldrich Chemical Co. St. Louis U.S.A. The solvents were of above $99 \%$ purity and hence used without further purification.

\section{Plant samples collection and processing}

The plant material (Toddalia asiatica stem) was collected during the short rain season in the month of July from its natural habitat at the slopes of Kajulu hills $\left(0^{\circ} 03^{\prime} \mathrm{S} 34^{\circ} 41^{\prime} \mathrm{E}\right)$ in the Lake Victoria basin, Kenya. Upon successfully authentication by plant taxonomist at the Department of Biological Sciences of Moi University Mr. Taabu Tepeny, specimen was deposited and voucher specimen accession number assigned as MU/BL/0038/2016. The mature plant stems were cut into pieces and carried in polythene bags to the laboratory for processing. Stem bark was scraped off, washed then dried at room temperature in open air for three weeks before grinding into fine powder using a hammer mill.

Stem bark powder $(500 \mathrm{~g})$ was extracted by merceration in 1 litre distilled water for 48 hours. The extract was filtered through Whatman No. 1 filter paper and freeze-dried using a laboratory lyophilizer (FD-1A-50). The extracts were then stored in sterile air-tight containers.

\section{Pathogenic test organisms}

Microbial organisms selected for screening efficacy of the prepared herbal antiseptic detergent was based on the recommendation of the National committee for clinical laboratory standards (NCCLS, 1992) as the important pathogens. Bacterial test strains were chosen in terms of their gram-staining properties. Gram positive included Methicillin Resistant Staphylococcus aureus (clinical isolate) while the gram negative were Pseudomonas aeruginosa (ATCC 27863), Escherichia coli (ATCC 2692) and Salmonella typhi (clinical isolate). Similarly the fungal test organisms were chosen categorically as yeasts entailing Candida albicans (ATCC 90038) and Candida tropicalis (ATCC 1750), while a dermatophyte as Microsporum gypseum (Clinical isolate). The clinical isolates were all identified with similar methods previously used by Nagy (2009).

\section{Design and Preparation of the herbal antiseptic detergent}

Tanguchi experimental design (Taguchi and Konishi, 1987) implemented on the Design-Expert version 7 was used for designing and optimization of the variables in preparation to attain the herbal antiseptic detergent with highest germicidal activity. From preliminary screening experiments the factors that would affect the response (Zones of Inhibition) were found to entail Sodium lauryl sulphates (SLS) concentration, percentage extract incorporated, temperature and the stirring time. These were all evaluated in single factor tests. A $\mathrm{L}_{9}\left(3^{4}\right)$ Taguchi Orthogonal Array was then used to define the optimal conditions per the selected factors to produce the herbal antiseptic detergent formulae and the optimum temperature and the stirring time for preparation. Each of the nine experiments were performed in triplicate and means reported.

According to results of optimization the herbal antiseptic detergent was then prepared by the conventional incorporation method for semi solid preparation heating with a thermostated oil bath magnetic stirrer with heating. Blank detergent was prepared similarly but without addition of the extract in same amount of plain distilled water. The formulated detergent was compared to commercial antiseptic handwash marketed in Kenya. 


\section{In-vitro antimicrobial evaluation}

In the assays, the negative control was the blank detergent prepared without extract; positive control was the commercial antiseptic hand wash. Freshly growing microorganisms were obtained by sub-culturing stocked isolates of bacterial strains onto Muller Hinton agar No. CM0047 (Oxoid Ltd.) and incubating at $37{ }^{\circ} \mathrm{C}$ for 24 hours. Meanwhile fungal strains on Sabouraud Dextrose Agar No. CM 0441 (Oxoid LTD) incubating at $30{ }^{\circ} \mathrm{C}$ for 72 hours. A 0.5 McFarland turbidity standard was prepared in sterile distilled water and inoculated uniformly onto the growth media. A $6 \mathrm{~mm}$ disc impregnated with the test solution was then aseptically placed onto the pates before incubating at respective temperatures. The zones of inhibition were then measured after 24 hours and 72 hours for antibacterial and antifungal assays respectfully.

\section{Model hand wash efficacy study}

Four volunteers groups (each three participants) were involved in the study categorized as those for the formulated herbal antiseptic detergent; for blank detergent; for commercial handwash and for tap water. The protocol was reviewed by the University Ethical Committee and all procedures approved as being within required ethical considerations. All the participants understood the protocol and informed consent was confirmed through duly signed acceptance to participate forms.

A rinse - wash method (Saad et. al., 2011) was adopted. This involved rinsing palm for 15 seconds with tap water; palm is then lathered with the desired test agent before rinsing again with water for 30 seconds. The drains of the palm rinse were collected separately into a sterile beaker. Enumeration of bacterial flora was then carried out by serially diluting and plating of the palm rinse drains on media plates and incubation at $37^{\circ} \mathrm{C}$ for 24 hours. Point inoculation method was adopted for viable microbial count.

\section{RESULTS AND DISCUSSION}

\section{Plant sample extraction percentage yield}

For the extraction of the phytocompounds from the stem bark, percentage yield was calculated as the ratio of the obtained freeze dried material to the total plant powder macerated in distilled water. Out of the $500 \mathrm{~g}$ of plant material extracted, a yield of upto $11 \%$ was afforded on freeze-drying. This was considered a satisfactorily amount for utilization in further tests.

\section{Design and Preparation of the herbal antiseptic detergent}

In the investigation of the optimum factors for the preparation of the antiseptic herbal detergent, two responses were considered as the bacterial inhibition against M.R.S. aureus and the fungal inhibition against $M$. gypsium. These were typical pathogenic organisms prevalent in the environment. The Taguchi Orthogonal Arrays of nine experiments gave the respective inhibitions for particular variables as indicated in table 1

On analysis of the responses together using the Design expert software, optimality was obtained as $10 \%$ water extract suspension to $5 \mathrm{~g}$ of SLS and solution made homogeneous by stirring for 15 minutes at $30^{\circ} \mathrm{C}$.

The optimized formula for the antiseptic herbal detergent was thus the one comprising of $5 \mathrm{~g}$ SLS, which gave a bacterial inhibition of $24 \mathrm{~mm}$ diameter. The other factors optimized were the percentage extract as $10 \%$ water suspension; and stirring time of 15 minutes at $30^{\circ} \mathrm{C}$, which also displayed a fungal inhibition of a zone reaching $22 \mathrm{~mm}$ in diameter this was therefore selected as the design for preparing the antiseptic herbal detergent.

\section{ANOVA analysis and Factors Percent contribution of the Taguchi orthogonal design}

ANOVA analysis was performed and results tabuleted in table 2 accordingly for sum of squares, degree of freedom, mean squares and the F-value. The various factors contribution was also calculated by the formulae in equation (i.)

Percent Contribution (PC)
(Waddad et. al., 2013)

$$
=\frac{\text { Sum of Squares }\left(S S_{F}\right)}{\text { Sum of Squares Total }\left(S S_{\text {Total }}\right)} X 100(i .)
$$

Table 1: Optimization array

\begin{tabular}{|c|c|c|c|c|c|c|}
\hline Run & $\begin{array}{l}\text { Factor 1: } \\
\text { amount }(\mathrm{g})\end{array}$ & $\begin{array}{c}\text { Factor 2: } \\
\% \text { Extract }(\%)\end{array}$ & $\begin{array}{c}\text { Factor 3: } \\
\text { Temperature } \\
\left({ }^{\circ} \mathrm{C}\right)\end{array}$ & $\begin{array}{c}\text { Factor 4: } \\
\text { Stirring time } \\
(\text { min })\end{array}$ & $\begin{array}{l}\text { Response 1: Bact- } \\
\text { Inhibition }(\mathbf{m m})\end{array}$ & $\begin{array}{l}\text { Response 2: Fungi- } \\
\text { Inhibition (mm) }\end{array}$ \\
\hline 1 & 2.5 & 20 & 30 & 45 & 18 & 14 \\
\hline 2 & 7.5 & 5 & 30 & 30 & 16 & 12 \\
\hline 3 & 7.5 & 20 & 25 & 15 & 20 & 16 \\
\hline 4 & 5 & 5 & 25 & 45 & 12 & 26 \\
\hline 5 & 2.5 & 10 & 25 & 30 & 8 & 14 \\
\hline 6 & 5 & 20 & 20 & 30 & 8 & 8 \\
\hline 7 & 2.5 & 5 & 20 & 15 & 6 & 8 \\
\hline 8 & 7.5 & 10 & 20 & 45 & 20 & 18 \\
\hline 9 & 5 & 10 & 30 & 15 & 24 & 22 \\
\hline
\end{tabular}


Table 2: ANOVA analysis and Factor's Percent contribution of the TOA.

\begin{tabular}{|c|c|c|c|c|c|}
\hline FACTOR & $\mathbf{S S}^{\mathbf{a}}$ & $\mathbf{D F}^{\mathbf{b}}$ & $\mathbf{M S}^{\mathbf{c}}$ & $\mathbf{F}^{\mathrm{d}}$ & $\mathrm{PC} \%{ }^{\mathrm{e}}$ \\
\hline \multicolumn{6}{|l|}{ Bacterial inhibition } \\
\hline A - SLS concentration & 210.89 & 2 & 105.44 & 70.95 & 20.3 \\
\hline B - \% Extract & 156.22 & 2 & 78.11 & 52.56 & 15.0 \\
\hline $\mathrm{C}$ - Temperature & 402.00 & 2 & 201.00 & 135.25 & 38.7 \\
\hline D - Stiring time & 270.22 & 2 & 135.11 & 90.92 & 26.0 \\
\hline Residual (error) & 23.78 & 2 & & & \\
\hline Totals & 1039.33 & 10 & & & \\
\hline \multicolumn{6}{|l|}{ Fungal inhibition } \\
\hline A - SLS concentration & 238.89 & 2 & 119.44 & 126.47 & 24.6 \\
\hline B - \% Extract & 150.22 & 2 & 75.11 & 79.53 & 15.5 \\
\hline $\mathrm{C}$ - Temperature & 288.89 & 2 & 144.44 & 152.94 & 29.7 \\
\hline D - Stiring time & 294.00 & 2 & 147.00 & 155.65 & 30.2 \\
\hline Residual (error) & 15.11 & 2 & & & \\
\hline Totals & 972 & 10 & & & \\
\hline
\end{tabular}

${ }^{\mathrm{a}}$ Sum of Squares

${ }^{\mathrm{b}}$ Degree of Freedom

${ }^{\mathrm{c}}$ Mean Sum of Squares

${ }^{\mathrm{d}} \mathrm{F}$ - value

${ }^{\mathrm{e}}$ Percent Contribution

Table 3: Zones of inhibition for antimicrobial assays

\begin{tabular}{|c|c|c|c|c|c|c|c|}
\hline \multirow[t]{2}{*}{ Test agent $(50 \mathrm{mg} / \mathrm{ml})$} & \multicolumn{7}{|c|}{ Zone of Inhibition (mm) } \\
\hline & M.R.S. aureus & P. aeruginosa & coli & S. typhi & C. albicans & C.tropicalis & M. gypseum \\
\hline Formulated antiseptic herbal detergent & $24.30 \pm 0.67^{d}$ & $18.00 \pm 0.58^{\mathrm{d}}$ & $16.00 \pm 0.58^{\mathrm{d}}$ & $19.67 \pm 0.67^{d}$ & $22.00 \pm 1.00^{\mathrm{d}}$ & $18.33 \pm 0.67^{\mathrm{d}}$ & $21.67 \pm 0.67^{d}$ \\
\hline Blank detergent & $14.00 \pm 0.58^{\mathrm{ce}}$ & $12.33 \pm 1.20^{\mathrm{c}}$ & $9.67 \pm 0.33^{\mathrm{c}}$ & $8.00 \pm 0.00^{\mathrm{c}}$ & $8.33 \pm 0.33^{\mathrm{c}}$ & $12.00 \pm 0.58^{\mathrm{c}}$ & $14.33 \pm 0.33^{\mathrm{ce}}$ \\
\hline Commercial hand wash & $21.67 \pm 0.33^{\text {be }}$ & $19.67 \pm 0.67^{b}$ & $13.67 \pm 0.33^{\mathrm{b}}$ & $18.33 \pm 0.33^{\mathrm{b}}$ & $20.33 \pm 0.88^{b}$ & $14.33 \pm 0.33^{\mathrm{b}}$ & $14.00 \pm 0.00^{\text {be }}$ \\
\hline Tap water & $6.00 \pm 0.00^{\mathrm{a}}$ & $8.00 \pm 1.15^{\mathrm{a}}$ & $8.00 \pm 1.15^{\mathrm{a}}$ & $10.00 \pm 0.58^{\mathrm{a}}$ & $9.67 \pm 0.67^{\mathrm{a}}$ & $8.00 \pm 0.00^{\mathrm{a}}$ & $8.33 \pm 1.20^{\mathrm{a}}$ \\
\hline
\end{tabular}

Values represent means \pm standard error.

For each organism, means with same letters within a column are not significantly different ( $\mathrm{p}<0.05$, Tukey’s standardised range test). N=3

Table 4: percent reduction in bacterial growth for palm rinse

\begin{tabular}{|c|c|c|c|}
\hline Test agent & Control (cfu/ml) & Test $(\mathrm{cfu} / \mathrm{ml})$ & $\%$ reduction \\
\hline Formulated Herbal detergent & $26.9 \times 10^{3}$ & $5.7 \times 10^{3}$ & $78.8 \%$ \\
\hline Blank detergent & $23.6 \times 10^{3}$ & $15.3 \times 10^{3}$ & $35.2 \%$ \\
\hline Commercial hand wash & $25.2 \times 10^{3}$ & $8.1 \times 10^{3}$ & $67.9 \%$ \\
\hline
\end{tabular}

\section{In-vitro antimicrobial evaluation}

In-vitro antimicrobial assays revealed that the formulated herbal detergent had significant activity against all the bacterial and fungal strains tested (table 3 ). The highest activity was against M.R.S. aureus $(24 \mathrm{~mm})$, this was significantly higher than the commercial hand wash $(22 \mathrm{~mm})$ while tap water registered no inhibition and the bank detergent only elicited an inhibition reaching $14 \mathrm{~mm}$ in diameter.

The formulated herbal detergent exhibited highest activity across all the strains of pathogenic microorganisms tested followed by the commercial handwash. Thus denoting the action of the active ingredient for which in the formulated herbal detergent was the extract of $T$. asiatica stem bark. Antibacterial antifungal activity of $T$. asiatica stem bark reported previously happens to be in the same range as that reported in this study. The findings of this study therefore confidently attributes the witnessed antiseptic activity to the phytocompounds in the plant stem bark based on the zones of inhibition that compares well to those obtained by Munyendo and group (2011) from the ethyl acetate extract of $T$. asiatica stem bark.

Meanwhile tap water registered minimal zone of inhibition diameter against all the pathogenic organisms screened, this is logically accepted since the water had no active ingredients compared to blank detergent that showed smaller diameter of inhibition whose activity could be charged to the cleaning capabilities as dirty removers.

Statistical analysis of the antimicrobial activity data to compare significance of means variation by t-tests revealed that there was significant variations at $\mathrm{p}<0.05$ level of confidence for most of the strains. M. R. S. aureus and M. gypseum inhibition did not significantly differ in particular with the blank detergent and commercial antiseptic detergent (table 3 ). This could be attributed to the fact that the bacteria $M$. R. S. aureus depicts resistance to common antiseptic agent while $M$. gypseum is a persistent dermatophyte that manifests as being chronic. This making susceptibility not differ significantly with this two particular test agents. However it is interesting to note that there was significant variation for the formulated antiseptic herbal detergent in comparison to tap water thus a confirmation statistically of the efficacy of the formulated herbal antiseptic product.

\section{Model hand wash efficacy study}

The skin carries a large number of bacterial and fungal organisms. Mainly the gram-positive bacteria are usually picked up from the various objects with which the skin comes in conduct with. The pathogenic microorganisms growth reduction (table 4) 
was obtained by use of equation (ii.), with data obtained from media plates bacteria enumeration after incubation of collected palm rinse up on washing with formulated herbal detergent, blank detergent and commercial hand wash

$$
\% \text { Reduction }=\frac{\text { control-Test agent }}{\text { control }} X 100 \ldots \text {. (ii) }
$$

(Saad et. al., 2011)

The formulated herbal detergent displayed greatest pathogenic microorganism reduction potential with $M . R$. S. aureus bacterial enumeration as the indicator. This was even higher than the commercial handwash and noted to be more than two times the blank detergent hence a confirmation of its efficacy. The activity against M.R.S. aureus is of significant interest, apart from the multi-drug resistance, $S$ aureus is one of the natural flora commonly found on human hands and face and may not be removed easily by routine washing. The potency therefore illustrated from the significant $\%$ reduction by the formulated herbal detergent $(78.8 \%)$ is remarkable presenting $T$. asiatica phytocompounds as promising active ingredients for formulation of antiseptic detergents. These results compares well with findings of Mann and Staba (2002) with formulations of herbal organic extracts against isolates from skin infections including boils and abscess.

\section{CONCLUSION}

The formulation containing the aqueous extracts of $T$. asiatica stem bark exhibited pronounced antimicrobial activity. This therefore suggest the use of formulated herbal antiseptic detergent as a superior and promising germicidal agent that comprises of non-synthetic active ingredients.

\section{ACKNOWLEDGEMENTS}

Author express their sincere gratitude to Maaida Abubaker Salim and Lilian Chepngetich for their tenacious workmanship during the laboratory experiments of this study. Authors also thankful to the entire School of Biological and Physical Sciences staff for accepting to participate as volunteers. We also acknowledge the Department of Chemistry and Biochemistry, Moi University for allowing access to necessary equipment for the study.

\section{Financial support and sponsorship: Nil.}

Conflict of Interests: There are no conflicts of interest.

\section{REFERENCES}

Duraipandiyan V and Ignacimuthu S. Antibacterial and antifungal activity of Flindersine isolated from the traditional medicinal plant, Toddalia asiatica (L.) Lam. J. Ethnopharmacol, 2009; 123(3): 494 498
Gidwani B, Alaspure RN, Duragkar NJ, Vijay S, Prakash SR, Shukla SS. Evaluation of a Novel Herbal Formulation in the Treatment of Eczema with Psoralea Corylifolia. Iran J Dermatol, 2010; 13: 122 - 7

Hemalatha S, Ayyappan T, Shanmugam S, Nagavalli D and Shrivijaya KT. Evaluation of antidiabetic and diuretic activity of polyherbal formulation. Indian J of Trad Knowledge, 2006; 5(4): $468-$ 470

Karunai RM, Balachandran C, Duraipandiyan V, Agastian P, Ignacimuthu S. Antimicrobial activity of Ulopterol isolated from Toddalia asiatica (L.) Lam.: a traditional medicinal plant. J Ethnopharmacol, 2012; 140(1): $161-165$

Mann C and Staba EJ. The chemistry, pharmacology and commercial formulationsof chamomile. In Craker LE, Simon JE, editors; Herbs, spices and medicinal plants recent advances in botany, horticulture and pharmacology U.S.A: Haworth Press Inc; 2002: 235 - 280

Maury E, Alzieu M, Baudel JL, Haram N, Barbut F, Guidet B et al. Availability of an alcohol solution can improve hand disinfection compliance in an intensive care unit. Am J Respir Crit Care Med, 2000; 162: $324-327$

Munyendo WLL, Orwa JA, Rukunga GM and Bii CC. Bacteriostatic and bactericidal activities of Aspilia mossambicensis, Ocimum gratissimum and Toddalia asiatica extracts on selected pathogenic bacteria. Research J of Med Plants, 2011; 5(6): 717 - 727

Nagy E. Maier T. Urban E. Terhes G and M. Kostrzewa. Species identification of clinical isolates of Bacteroides by matrix-assisted laser-desorption/ionization time-of-flight mass spectrometry. Clinical microbial and infections; 2009: 15(8): 796 - 802

NCCL, National committee for clinical laboratory standards; performance standards for antimicrobial disk susceptibility tests 4th Edition. Approved standards NCCLS document $\mathrm{M}_{2}-\mathrm{A}_{4}$, Villanora 1992.

Orwa JA, Jondiko IJO, Minja RJA, and Bekunda M. The use of Toddalia asiatica (L) Lam. (Rutaceae) in traditional medicine practice in East Africa. J. of Ethnopharmacol, 2008; 115 : 257-262

Pittet D. Clean hands reduce the burden of disease. Lancet, 2005; 366: $185-187$.

Pittet D and Boyce JM. Hand hygiene and patient care: pursuing the semmelweis legacy. Lancet Infect Dis, 2011; 1:9-20

Pittet D, Hugonnet S, Harbarth S, Mourouga P, Sauvan V, Touveneau $S$ and Perneger TV. Effectiveness of a hospital-wide programme to improve compliance with hand hygiene. Lancet, 2000; 365:1307 - 1322

Roose-Amsaleg and Laverman AM. Do antibiotics have environmental side-effects? Impact of synthetic antibiotics on biogeochemical processes. Environ Sci Pollut Res Int, 2016; 23(5): 4000 4012

Saad AH, Gamil SN, Kadhim RB and Samour R. Formulation and evaluation of herbal hand wash from Matricaria chamomilla flowers extracts. Int. J. Res in Ayurveda and Pharm, 2011; 2(6): 1811 - 1813

Taguchi $\mathrm{G}$ and Konishi S. Orthogonal arrays and linear graphs. Dearborn, MI: 1987. American Supplier Institute, Inc.

UNICEF Report; Maternal, newborn and child health working paper on Access to healthcare through community health workers in East and Southern Africa United Nations Children's Fund (UNICEF), New York, 2014

Waddad YA, Abbad S, Yu F, Munyendo LLW, Wang J, Lv H, and Zhou J. Formulation, characterization and pharmacokinetics of Morin hydrate niosomes prepared from various non-ionic surfactants. Int. J. Pharm 2013; 456: 446 - 458.

How to cite this article:

Were L. L. Munyendo, Ambrose K. Kiprop., Design, preparation and evaluation of germicidal Toddalia asiatica herbal antiseptic detergent. J App Pharm Sci, 2016; 6 (11): 100-104. 